serem Fragmente, dafs seine Zahl im Gegensatz zu den anderen Rezensionen des Malalastextes so nahe an die wahre Zahl des Africanus herantritt. Bei einer Herstellung der wahren Götterzahlen des Manethos, wie ich sie Africanus II S. $58 \mathrm{ff}$. versucht habe, mülste also zweifellos diese echte Zahl des Helios berücksichtigt werden. Indessen da, so lange wir über die Zahlen des Sos und des Keb gar nicht unterrichtet sind, ein irgendwie sicherer Herstellungsversuch nicht möglich ist, unterlasse ich hier denselben.

Jena.

H. Gelzer.

\title{
Nachtrag zu S. 152.
}

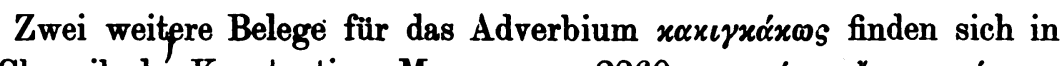

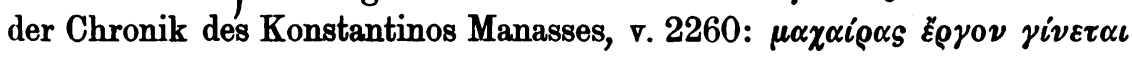

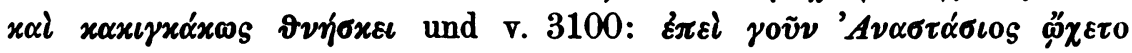

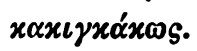

Eine interessante Anwendung des Adjektivums xaxós in Verbindung mit xaxĩs bietet Gregorios Akindynos (bei Th. Uspenskij, Das Syno-

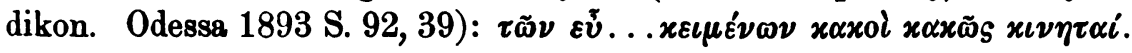

Riga.

E. Kurtz. 